\title{
Indian Society of Vascular and Interventional Radiology Expert Consensus Statements for Ablation in Hepatocellular Carcinoma: Part II
}

\author{
Pankaj Gupta1,@ Shyamkumar N. Keshava² Naveen Kalra ${ }^{1} \quad$ Sreedhara B. Chaluvashetty ${ }^{1}$ \\ Amar Mukund $^{3}$ Shuvro H. Roy-Choudhury ${ }^{4}$ Sanjay Saran Baijal ${ }^{5} \quad$ Anubhav Khandelwal ${ }^{5}$ \\ Venkatesh Hosur Ananthashayana ${ }^{3}$ Sathya Narayanan R. ${ }^{2}$ Suyash S. Kulkarni ${ }^{6,7}$ Nitin Sudhakar Shetty ${ }^{6,7}$ \\ Arun Gupta $^{8}$ Sanjay Gupta ${ }^{9}$
}

\footnotetext{
${ }^{1}$ Department of Radiodiagnosis and Imaging, Postgraduate Institute of Medical Education and Research, Chandigarh, India

${ }^{2}$ Department of Interventional Radiology, Division of Clinical Radiology, Christian Medical College, Vellore, Tamil Nadu, India

${ }^{3}$ Department of Interventional Radiology, Institute of Liver and

Biliary Sciences, New Delhi, India

${ }^{4}$ Department of Radiology, NH Group of Hospitals, Kolkata, West Bengal, India

${ }^{5}$ Department of Interventional Radiology, Medanta, The Medicity, Gurgaon, Haryana, India

${ }^{6}$ Department of Interventional Radiology, Tata Memorial Hospital, Mumbai, Maharashtra, India

${ }^{7}$ Homi Bhabha National Institute, Mumbai, Maharashtra

${ }^{8}$ Department of Interventional Radiology, Sir Ganga Ram Hospital, New Delhi, India

${ }^{9}$ Department of Interventional Radiology, MD Anderson Cancer

Center, Texas, United States
}

J Clin Interv Radiol ISVIR:2020;4:175-183
Address for correspondence Naveen Kalra, MD, Department of Radiodiagnosis and Imaging, Postgraduate Institute of Medical Education and Research, Sector 12, Chandigarh 160012, Chandigarh, India (e-mail: navkal2004@yahoo.com).

\begin{abstract}
Locoregional therapies play an important role in the management of hepatocellular carcinoma (HCC). Percutaneous ablation is one of the most commonly employed nonsurgical methods for treating very early and early HCC. For small HCC, ablation is potentially curative and competes with surgical resection. The widespread availability and the spectrum of ablative techniques mandate uniform approach among interven-

Keywords

- ablation

- guidelines

- RFA tional radiologists. Thus, it is desirable to have a consensus regarding various aspects of the liver ablation. This article represents a consensus document of the experts from the Indian Society of Vascular and Interventional Radiology involved in the care of patients with HCC. The statements are presented in two parts.
\end{abstract}

\section{Guiding Principle and Objectives}

Hepatocellular carcinoma (HCC) is the one of the most common cancers worldwide and is the leading cause of cancer-related mortality. ${ }^{1}$ The majority of HCC occurs in the setting of cirrhosis and are diagnosed during surveillance. ${ }^{2}$ The therapies of HCC have evolved over the past 20 years. Broadly, the therapeutic options for HCC are hepatic resection (HR),

published online

21-Oct-2020
DOI https://doi.org/

$10.1055 / \mathrm{s}-0040-1715775$

ISSN 2457-0214. liver transplantation, locoregional therapies including percutaneous ablation, transarterial chemoembolization (TACE), transarterial radioembolization (TARE), stereotactic body radiation therapy, and systematic therapies including immunotherapies. ${ }^{3}$ The treatment in an index patient is based on the tumor characteristics, including mainly the number and size of tumor nodules, the status of the portal vein, liver function, and performance status of the patient. Barcelona Clinic Liver
(C)2020. Indian Society of Vascular and Interventional Radiology.

This is an open access article published by Thieme under the terms of the Creative Commons Attribution-NonDerivative-NonCommercial-License, permitting copying and reproduction so long as the original work is given appropriate credit. Contents may not be used for commercial purposes, or adapted, remixed, transformed or built upon. (https://creativecommons.org/licenses/by-nc-nd/4.0/).

Thieme Medical and Scientific Publishers Pvt. Ltd. A-12, 2nd Floor, Sector 2, Noida-201301 UP, India 
Cancer represents one of the most widely used approaches when assessing a patient for management. ${ }^{3}$ Percutaneous ablation is a commonly utilized treatment for very early and early HCC. ${ }^{4}$ There are several percutaneous ablation methods. The most commonly used is radio frequency ablation (RFA), followed by microwave ablation (MWA), and cryoablation. The other techniques are irreversible electroporation (IRE), high-intensity focused ultrasound, and laser ablation. As many tertiary care centers across India are offering liver tumor ablation, uniformity must be achieved. There is a lack of a document for the guidance of interventional radiologists involved in the ablation of HCC.

The present consensus aimed to generate statements about various aspects of ablation procedures for HCC to bridge a gap in the existing practice and the one supported by existing literature. The expert group comprising of interventional radiologists involved in the management of HCC performed multiple systematic reviews of the literature after selecting key questions. Grading of Recommendations Assessment, Development, and Evaluation system was used for grading evidence and strength of recommendation ${ }^{5}$ (- Table 1).

\section{Key Questions}

The guideline developers identified key questions that the interventional radiologists are faced with while considering patients with HCC for percutaneous ablation. Following questions were included: -

1. What should be the aim of ablation?

2. Till what size, ablation may be performed?

3. What should be the target ablation margin?

4. Should adults with Child-Pugh class C cirrhosis or performance status $>1$ undergo ablation?

5 . What is the pre-procedure platelet count and international normalized ratio below which ablation is contraindicated?

6. Which imaging modality should be preferred for the guidance of ablation procedure?

7. Is there a role of fusion imaging or navigation techniques during an ablation?

8. What is the role of prophylactic antibiotics before ablation?

9. What strategies should be adopted for ablation of lesions at high risk locations?

10. Should ascites be drained before ablation?

11. What is the role of transient vascular occlusion devices to prevent heat sink in lesions close to blood vessels?

12. Which is the preferred ablative method for perivascular tumors?

13. Should immediate postablation contrast imaging be routinely performed after ablation?

14. How should perihepatic hemorrhage postablation be managed?

15. What should be the protocol for postablation imaging?

16. What is the treatment of postablation residual or recurrent lesions?

17. What is the role of combination therapies with ablation? This part of the article deals with the questions 11 to 17.
Table 1 GRADE approach

\begin{tabular}{|c|c|c|}
\hline $\begin{array}{l}\text { Rating the } \\
\text { quality of } \\
\text { evidence }\end{array}$ & Definition & Type of evidence \\
\hline High & $\begin{array}{l}\text { Further research is } \\
\text { very unlikely to } \\
\text { change our } \\
\text { confidence in the } \\
\text { estimate of effect }\end{array}$ & RCT \\
\hline Moderate & $\begin{array}{l}\text { Further research } \\
\text { is likely to have an } \\
\text { important impact } \\
\text { on our confidence in } \\
\text { the estimate of effect } \\
\text { and may change the } \\
\text { estimate }\end{array}$ & $\mathrm{RCT}$ \\
\hline Low & $\begin{array}{l}\text { Further research is } \\
\text { very likely to have an } \\
\text { important impact on } \\
\text { our confidence in the } \\
\text { estimate of effect and } \\
\text { is likely to change the } \\
\text { estimate }\end{array}$ & $\begin{array}{l}\text { Observational } \\
\text { study }\end{array}$ \\
\hline Very low & $\begin{array}{l}\text { Any estimate of effect is } \\
\text { very uncertain }\end{array}$ & $\begin{array}{l}\text { Any other } \\
\text { evidence }\end{array}$ \\
\hline $\begin{array}{l}\text { Rating the } \\
\text { strength of } \\
\text { recommenda- } \\
\text { tions }\end{array}$ & Implications & Determinants \\
\hline Strong & $\begin{array}{l}\text { Population: Most people } \\
\text { in this situation would } \\
\text { want the recommended } \\
\text { course of action and } \\
\text { only a small proportion } \\
\text { would not } \\
\text { Health care workers: } \\
\text { Most people should } \\
\text { receive the recom- } \\
\text { mended course of } \\
\text { action } \\
\text { Policy makers: } \\
\text { The recommendation } \\
\text { can be adapted as } \\
\text { policy in most } \\
\text { situations }\end{array}$ & $\begin{array}{l}\text { Quality of } \\
\text { evidence } \\
\text { Balance of benefit } \\
\text { and harm } \\
\text { Patient values and } \\
\text { preferences } \\
\text { Resources and } \\
\text { costs }\end{array}$ \\
\hline Conditional & $\begin{array}{l}\text { Population: Most of the } \\
\text { people in this situation } \\
\text { would want the } \\
\text { recommended course } \\
\text { of action, but many } \\
\text { would not } \\
\text { Health care workers: } \\
\text { Be prepared to } \\
\text { help patients make } \\
\text { a decision that is } \\
\text { consistent with their } \\
\text { values using decision } \\
\text { aids and shared decision } \\
\text { making } \\
\text { Policy makers: There is } \\
\text { a need for substantial } \\
\text { debate and involvement } \\
\text { of stakeholders }\end{array}$ & \\
\hline
\end{tabular}

Abbreviations: GRADE, Grading of Recommendations Assessment, Development, and Evaluation; RCT, randomized controlled trial. 


\section{What Is the Role of Transient Vascular Occlusion Devices to Prevent Heat Sink in Lesions Close to Blood Vessels?}

\section{Key Statement}

Temporary percutaneous occlusion of the portal vein or hepatic vein during RFA is safe and increases the diameter of the ablation zone. No extensive studies are available to recommend occlusion of the hepatic artery during RFA.

Quality/certainty of evidence: low

Strength of recommendation: conditional

\section{Evidence and rationale}

Perivascular HCC is defined as a tumor having contact with first- or second-degree branches of portal vein or hepatic vein measuring $3 \mathrm{~mm}$ or greater in diameter. ${ }^{6}$

A series of 10 patients with perivascular tumors larger than $3.5 \mathrm{~cm}$ treated with RFA by temporarily occluding hepatic or segmental portal vein showed it to be a safe procedure. ${ }^{7}$ Later, a prospective study by the same group evaluated the role of percutaneous transient balloon occlusion of portal or hepatic vein during RFA of perivascular tumor. The rate of local tumor progression (LTP) was lower for perivascular tumors smaller than $3.5 \mathrm{~cm}$. However, balloon occlusion did not affect the results for tumors larger than $3.5 \mathrm{~cm} .{ }^{8}$ The data regarding hepatic artery occlusion during RFA is limited. A study demonstrated that RFA with balloon occlusion of the common hepatic artery can achieve a significantly larger diameter of coagulation necrosis as compared with standard RFA. ${ }^{9}$ However, the complications of hepatic artery balloon occlusion during RFA have not been studied. A study comprising four patients showed that balloon occlusion of both the hepatic artery and hepatic vein resulted in an ablation diameter of 50 to $60 \mathrm{~mm}$ using a single electrode with no major complications. ${ }^{10}$

\section{Which Is the Preferred Ablative Method for Perivascular Tumors?}

\section{Key Statements}

1. RFA with cluster electrodes or multibipolar electrodes are recommended for perivascular $\mathrm{HCC} \leq 5 \mathrm{~cm}$. MWA is an acceptable alternative.

2. IRE may be recommended for perivascular $\mathrm{HCC} \leq 2 \mathrm{~cm}$ as an alternative for thermal ablation.

3. Cryoablation may be used as an alternative to RFA in perivascular $\mathrm{HCC} \leq 3 \mathrm{~cm}$ in diameter.

Quality/certainty of Evidence: low

Strength of recommendation: conditional

\section{Evidence and rationale}

MWA has certain advantages when compared with RFA. ${ }^{11}$ These include a higher tissue temperature, larger zone of ablation in shorter times, insensitivity to carbonization, and reduced susceptibility to heat sink effect. ${ }^{12}$ In a study evaluating the efficacy of MWA for early HCC, 113 propensity matched pairs (perivascular tumors and tumors away from large vessels) were evaluated. There was no significant difference in LTP, overall survival (OS), and complications between the two groups. ${ }^{13} \mathrm{~A}$ retrospective study comparing four different thermal ablative methods (monopolar RFA, MWA, cluster RFA, and multibipolar RFA) for the management of perivascular HCC $\leq 5 \mathrm{~cm}$ found that the overall LTP was significantly higher in nodules ablated by single-applicator techniques (monopolar RFA or MWA) when compared with nodules treated by multiapplicator techniques (multibipolar RFA or cluster RFA). ${ }^{14}$ In another study by van Tilborg et al evaluating the efficacy of RFA versus MWA for colorectal metastases in proximity to a large vessel or bile duct, both RFA and MWA were found to be safe and equally effective for perivascular tumors. ${ }^{15}$

IRE is a nonthermal ablation method that involves a series of high voltage currents and achieves cell death by creating irreversible pores in cellular bilipid membranes..$^{16}$ As the predominant pathway for cell death is apoptosis, it has been demonstrated in experimental and clinical studies that the peritumoral connective tissue, vessels, and bile ducts are not damaged. ${ }^{17}$ Hence, IRE seems to be an attractive alternative option for tumors near the porta hepatis or perivascular tumors. ${ }^{18}$ IRE has been shown to be safe and effective alternative for inoperable HCC that may not be ideal candidates for thermal ablative techniques. ${ }^{19}$ Although animal model-based studies have shown that an ablation zone of more than $6 \mathrm{~cm}$ may be achieved, clinical studies have shown that IRE has a poor efficacy with tumors $>3 \mathrm{~cm} .{ }^{20}$

The advantage with cryoablation is the ability to precisely monitor the ablated area using ultrasound (US), computed tomography (CT), or magnetic resonance imaging (MRI). RFA was shown to be superior to cryoablation in a meta-analysis, as it had lower complication rate and LTP although there was no significant difference in mortality. ${ }^{21}$ However, a randomized controlled trial (RCT) reported that LTP was significantly lower in cryoablation than RFA. ${ }^{22}$ The complications, tumor-free survival, and OS were not significantly different. Another recent study revealed that cryoablation was effective and did not result in vascular complications in patients with perivascular HCC. ${ }^{23}$ A study comparing RFA with cryoablation in patients with perivascular HCC found that cryoablation is an effective alternative to RFA for $\mathrm{HCC} \leq 3 \mathrm{~cm} .{ }^{24}$

\section{Should Immediate Postablation Contrast Imaging Be Routinely Performed after Ablation?}

\section{Key Statement}

Postcontrast imaging plays an essential role in assessing the ablation zone and the presence of residual tumors so that ablation can be repeated in the same setting. Besides, imaging helps in the early detection of complications and timely management.

Quality/certainty of evidence: low

Strength of recommendation: conditional 


\section{Evidence and rationale}

In a study by Yoon et al comprising 36 patients with 43 HCCs, multiphase CT was performed before and immediately after RFA. ${ }^{25}$ Additionally, MRI was performed 1 to 3 days (mean, 1.25 days) after RFA. The conspicuity of the ablated tumor margin was significantly higher on MRI compared with CT. The ability to differentiate post-RFA hyperemia from the residual lesion was significantly higher for MRI. Moreover, there was a higher interobserver agreement for MRI than for CT. The authors concluded that contrast-enhanced MRI could be used as a surveillance imaging tool after RFA. In a study by Lekht et al, 64 patients underwent RFA of liver tumors. ${ }^{26}$ Patients were divided into two groups based on whether postablation contrast-enhanced ultrasound (CEUS) was utilized. Thirty-six patients underwent standard RFA without postablation CEUS, while 28 patients underwent CEUS following ablation. At first follow-up imaging, six patients had residual tumors, and all these patients belonged to the group that underwent standard RFA. None of the patients who underwent CEUS following the procedure had a residual tumor. The utility of CEUS in predicting early therapeutic response to ablation was assessed by another study comprising 78 HCCs. ${ }^{27}$ CEUS was performed 20 to 30 minutes after the RFA. Contrast-enhanced MRI was performed 1 month after RFA. CEUS had a concordance of $97.4 \%$ with MRI in the assessment of the therapeutic efficacy of RFA. In a study by Xu et al comprising 95 liver tumors in 76 patients who underwent RFA/MWA, postprocedure three-dimensional US-CEUS fusion assessment was performed to guide supplementary ablation in cases of residual lesions during the same session. ${ }^{28}$ The success rate of fusion was $93.7 \%$. Supplementary ablation was performed in 30 lesions. The authors concluded that three-dimensional US-CEUS fusion allows immediate assessment of response and guides additional ablation. Studies have reported the value of conventional US in assessing response to ablation. In a study by Minami et al, the utility of US-US overlay images whereby the preablation US images were superimposed on the postprocedure images to assess the ablative margin was investigated. ${ }^{29}$ In this study, 68 HCC nodules in 35 patients were treated with RFA. The US-US overlay images accurately evaluated the response in 92.6\% of the HCC when compared with an early dynamic CT scan. In a study by Rajesh et al, CEUS was utilized for guiding the ablation of HCC that were poorly defined on US and unenhanced $\mathrm{CT}^{30}$ Postablation CEUS was performed to document complete ablation. In this study comprising 19 HCCs in 14 patients, complete ablation was achieved in all patients. The authors concluded that CEUS is a useful tool for the ablation of early-stage HCC. Postablation color Doppler evaluation of the tract may identify active bleeding after the removal of the electrode. ${ }^{31}$ Immediate postprocedure CT angiography may identify perihepatic hematoma or active contrast extravasation. However, presence of these findings has not been shown to predict unstable bleeding or need for angioembolization. ${ }^{32,33}$ Moreover, there are no recommendations on the routine use of postablation CT.

\section{How Should Perihepatic Hemorrhage Postablation Be Managed?}

\section{Key Statement}

The risk of significant bleeding with ablation of HCC is low $(<2 \%)$. Most venous bleeds are self-limited and can be managed conservatively. Endovascular embolization or surgery may be required for arterial bleeding.

Quality/certainty of evidence: low

Strength of recommendation: conditional

\section{Evidence and rationale}

The complication of intraperitoneal bleeding or subcapsular hematoma is of concern in patients undergoing ablation for HCC owing to two main reasons. ${ }^{34}$ Most of the patients with cirrhosis have deranged coagulation parameters. Hemorrhagic complications though rare are considered as major complications and may lead to significant morbidity and mortality in these patients. Cases of hepatic artery rupture with the formation of pseudoaneurysms have been reported earlier and have been the cause of death in these patients. ${ }^{35,36}$ Appropriate management of bleeding complications following the ablation of liver tumors is essential. ${ }^{37}$ Venous bleeds in postablation settings are self-limiting, while arterial bleeds are best managed with transarterial embolization. ${ }^{38}$

\section{What Should Be the Protocol for Postablation Imaging?}

\section{Key Statement}

It is recommended to perform first follow-up scan at 1 month after ablation. Thereafter, imaging is recommended every 3 months for the first year.

Quality/certainty of evidence: low

Strength of recommendation: conditional

\section{Evidence and rationale}

Optimization of imaging modality, acquisition protocols, and consistency in the use of the same modality and protocol throughout follow-up examinations are vital for proper assessment of tumor response to ablation. Contrast-enhanced CT or contrast-enhanced dynamic MRI is the recommended imaging modality to follow patients after ablation. ${ }^{39,40}$ The administration of intravenous contrast is recommended for all studies if not contraindicated. Mandatory arterial and portal venous phase imaging of the liver, with the equilibrium phase depending on the clinical practice and findings in the dual-phase acquisition, is suggested. ${ }^{41}$ A review of contiguous thin slices with no interslice gap is mandatory not to miss the smaller lesions. The choice of imaging modality depends on the availability, institutional preference, and expertise. Following ablation, the first follow-up imaging is done at 1 month after treatment. For early detection of recurrence and clinical evaluation of decompensation, follow-up scans are suggested every 3 months during the first year and surveillance every 
6 months after that.$^{41}$ However, Liu et al in their study on optimal monitoring divided the patients into high and low recurrence risk groups and followed up for rate of recurrence with short (less than four months) and long intervals (4-6 months interval). ${ }^{42}$ Based on the recurrence rate and OS at 1, 3, and 5 years, they proposed the risk-based surveillance strategy to reduce the number of scans, radiation dose, and cost. Another study by Boas et al reported that the optimal schedule for surveillance after liver directed therapies is $2,4,6,8,11,14,18$, and 24 months in the first 2 years. ${ }^{43}$ Mikami et al showed that 4-month interval for CT surveillance of HCC after RFA detects majority of the recurrent nodules at a stage where repeat RFA (rRFA) is feasible. ${ }^{44}$ Granata et al reported that hepatocyte specific contrast-enhanced MRI is more useful than multiphase CT in the assessment of HCC after RFA. ${ }^{45}$

\section{Which Diagnostic Criteria Should Be Applied for the Detection of Residual or Recurrent Lesion after Ablation?}

\section{Key Statements}

1. Ablation zone appears as a nonenhancing area with or without a smooth enhancing peripheral rim. The enhancing rim is relatively concentric, symmetric, and uniform with smooth inner margins.

2. Modified response evaluation criteria for solid tumors (mRECIST) or liver imaging reporting and data system (LI-RADS) locoregional treatment response (LR-TR) assessment criteria is recommended for the assessment of response/disease progression following locoregional therapies.

Quality/certainty of evidence: low

Strength of recommendation: conditional

\section{Evidence and rationale}

Residual tumor appears as a peripheral, nodular, or ill-defined area of arterial phase enhancement with washout on the venous phase. ${ }^{41}$ On T2-weighted images, the residual tumor appears hyperintense compared with the hypointense signal of the coagulated area. ${ }^{41}$ This shows enhancement on arterial phase and washout on delayed phase images. LTP is the appearance of tumor foci at the edge or within the ablation zone, after adequate ablation and an absence of viable tissue has been documented using imaging criteria at baseline follow up. ${ }^{46,47}$

For equivocal lesions, dynamic contrast-enhanced MRI with diffusion-weighted imaging (DWI) and apparent diffusion coefficient (ADC) mapping act as useful adjunctive techniques and allow differentiation between tumor and post-treatment changes. ${ }^{48}$ Low ADC value in the area of hyperintense signal on T2-weighted image is suggestive of viable tumor. Mohamed et al evaluated 56 patients with 74 HCCs treated with locoregional therapies (TACE or RFA) using DWI. DWI-MRI showed a sensitivity of $98.96 \%$ and specificity of $92.90 \%$, for detecting residual tumors. ${ }^{48}$ The dynamic contrast-enhanced MRI (with subtraction and perfusion maps) showed higher accuracy, sensitivity, and specificity. The combination of DWI and dynamic contrast-enhanced MRI yielded 100\% sensitivity, 100\% specificity, and $99.09 \%$ accuracy. Mahmoud et al, in their study, documented significantly lower mean ADC values $(0.91 \pm 0.09)$ in the recurrent lesions as compared with ablation zone (1.36 \pm 0.18 ) or postablation images (1.29 \pm 0.12). ${ }^{49}$ Positron emission tomography (PET)-CT can be used for early detection of recurrent disease in those patients where preablation PET-CT showed F-fluorodeoxyglucose -avid lesions. ${ }^{18}$ Imaging appearance of remote intrahepatic distant recurrence and extrahepatic recurrence/metastasis is like that of a nonablated lesion. ${ }^{50}$ Recent studies have evaluated the performance of LI-RADS for response assessment. ${ }^{51,52}$ In a retrospective study by Chaudhry et al, LI-RADS v2018 was used to assess the response in patients who underwent ablation and histopathological evaluation of explant liver..$^{51} \mathrm{~A}$ total of 53 lesions in 36 patients were evaluated. Interreader agreement for treatment response category was high. The sensitivity and specificity of tumor necrosis were 40 to $77 \%$ and 85 to $97 \%$, respectively, when LR-TR equivocal lesions were considered as nonviable. However, when these lesions were treated as viable, the sensitivity increased to 81 to $87 \%$, and specificity reduced to 81 to $85 \%$. Out of the six (11\%) LR-TR equivocal lesions, five lesions showed incomplete necrosis at explant histopathological evaluation. A recent study by Seo et al comparing mRECIST with LI-RADS for treatment response assessment reported better performance of LI-RADS v2017 compared with mRECIST for CT-based assessment. ${ }^{52}$ At the same time, there was no difference based on MRI assessment.

\section{What Is the Treatment of Postablation Residual or Recurrent Lesions?}

\section{Key Statements}

1. Residual lesions are managed with repeat ablation if $<3 \mathrm{~cm}$ and well defined or TACE/TARE if $>3 \mathrm{~cm}$ and ill defined.

2. Recurrent lesions are managed with repeat ablation, resection, or salvage liver transplantation (SLT) based on the functional status of liver and macroscopic features of recurrent tumor.

Quality/certainty of evidence: low Strength of recommendation: conditional

\section{Evidence and rationale:}

If the residual lesion is focal and well defined along the periphery or within the ablation zone and is less than $3 \mathrm{~cm}$, then repeat ablation should be considered..$^{53}$ If the residual lesion is irregular, diffusely scattered along the margins of the ablated lesion, overall size more than $3 \mathrm{~cm}$, and along the subcapsular region or in a difficult location, then transarterial therapies should be considered (TACE or TARE) based on portal vein status and Child-Pugh score. ${ }^{53}$ There is no consensus on standardized treatment strategy for a recurrent lesion at present. The choice of treatment depends on two critical factors: the functional status of the liver and macroscopic 
features of the recurrent tumor. Options are rRFA and SLT. ${ }^{54}$ Aggressive treatment strategy should be employed in cases of recurrence as they signify the aggressive nature of the tumor, preferably with resection or SLT whenever feasible. ${ }^{54}$

In the study by Chan et al, rRFA in recurrent HCC was associated with early re-recurrence and reduced median disease-free survival as compared with resection and SLT group. ${ }^{54}$ In this study, 87 patients with recurrent HCC were treated with SLT, resection, and rRFA. The 1-, 3-, and 5- year disease-free survival rates were significantly lower after rRFA.

\section{What Is the Role of Combination Therapies with Ablation?}

\section{Key Statements}

1. A combination of ablation procedure with TACE offers survival benefit compared with ablation alone; the benefit is more in HCC greater than $3 \mathrm{~cm}$ in size.

2. Irrespective of the timing of combination, that is, sequential or simultaneous, within 4 weeks, the outcomes of combination therapy are better than monotherapy.

Quality/certainty of evidence: Moderate

Strength of recommendation: Strong

\section{Evidence and rationale}

RFA or MWA are equivalent therapeutic options to surgical resection for small, early-stage $\mathrm{HCC}^{55}$ Heat sink restricts their efficacy in large lesions. A combination of RFA/MWA with TACE potentiates necrosis, increases the clearance of micrometastasis, leading to reduced recurrence, improved OS and progression-free survival (PFS) with no significant difference in major complications. ${ }^{56}$

In a meta-analysis by $\mathrm{Ni}$ et al comprising eight RCTs, 306 patients underwent RFA plus TACE, while 292 patients underwent RFA alone. ${ }^{56}$ The former group showed significantly higher 1, 2, and 3 years OS. This benefit was seen for intermediate and large-sized HCC and not the small-sized HCC. Additionally, patients in the combination groups had a lower LTP rate and higher PFS, with no significant difference in the major complications. In an RCT by Peng et al, TACERFA treatment was found to be superior to RFA alone in OS and recurrence-free survival. ${ }^{57}$ In a study by Abdelaziz et al, TACE was followed by MWA $(n=45)$ or RFA $(n=22)$ within 2 weeks later. TACE-MWA was found to give higher complete response rates than TACE-RFA for lesion 3 to $5 \mathrm{~cm} .{ }^{58}$ However, there was no survival benefit.

Different investigators have adopted different protocols for the combination of RFA with TACE. In the study by Song et al, 201 patients with single $\mathrm{HCC} \leq 5.0 \mathrm{~cm}$ or up to three HCC $\leq 3.0 \mathrm{~cm}$ were treated with TACE+RFA (performed 4 weeks after TACE) $(n=87)$, TACE $(n=71)$, and RFA alone $(n=43) .{ }^{59}$ The TACE + RFA group showed significantly lower local recurrence than the RFA $(p=0.008)$ or TACE alone $(p=0.011)$. The OS at 1,3 , and 5 years was significantly better in the TACE + RFA group compared with the RFA group. However, the OS was not significantly different compared with the TACE group
(97.2\%; $p=0.1$ ). Subgroup analysis revealed better long-term survival in tumors $<3 \mathrm{~cm}$ treated with TACE + RFA than those treated with TACE or RFA alone. In the study by Chen et al, MWA was performed within two weeks of TACE. ${ }^{60}$ After initial treatments, significantly greater number of patients in the TACE-MWA group (92.1\%) had complete necrosis when compared with the TACE group (46.3\%). At 6 months, the TACE-MWA group had better tumor responses compared with TACE alone group.

In the RCT by Kamal et al, evaluating TACE vs TACE-RFA, RFA was performed within 5 days of the TACE. ${ }^{61}$ Complete response rates at 1 month were 100 and 84\% for combined RFA-TACE therapy and TACE only, respectively. One-year disease-free survival rate was 56 and 24\% in RFA-TACE and TACE groups, respectively. The OS rate was also significantly higher in the combination group ( 88 vs. $80 \%$ ). Xu et al performed TACE immediately after RFA in the same session in 93 patients with solitary massive intermediate stage HCC. One, 3-, 5-, and 7-year survival rate was 94.4, 52.3, 26.1, and $14.1 \%$, respectively. ${ }^{62}$

In another study, patients with solitary intermediate sized HCC were randomized to receive either RFA alone or RFA+TACE (on the same day). ${ }^{63}$ Fewer sessions of RFA were required when combination therapy was utilized. LTP at 3 years was significantly higher in the RFA group compared with the TACE-RFA groups (39 vs. 6\%, $p=0.012$ ). However, the OS at 3 years was not significantly different between the two groups. In the meta-analysis by Dong et al comprising five RCTs, RFA was compared with RFA plus TACE for small HCC. ${ }^{64}$ There were no significant differences in the 1 -year ( $p=0.27$ ) or 3 -year $(p=0.183)$ OS. However, the 5-year OS was significantly higher in patients treated with RFA+TACE than those treated with RFA alone. In the study by Chen et al, tumors $<5 \mathrm{~cm}$ subjected to TACE were compared with those undergoing TACE+MWA. ${ }^{60}$ Subgroup analysis showed that for tumors $<3 \mathrm{~cm}$, TACE-MWA showed longer time to progression and better OS than TACE alone. For tumors $<5 \mathrm{~cm}$, TACE-MWA led to longer time to progression, but there was no significant difference in the OS.

In the study by Song et al, patients with a tumor size $<3 \mathrm{~cm}$ who underwent TACE + RFA had significantly better long-term survival than those who underwent only TACE or RFA. ${ }^{59}$

Other adjuvant therapies in the combination regimen are being investigated. An ongoing trial is investigating simultaneous TAE and ablation versus sequential TACE followed by ablation for large HCC. ${ }^{65}$

In the propensity-matched cohort study of 228 patients of HBV-related HCC, patients were divided into two groups: those that underwent RFA ( $n=103$ ) and those who received RFA + antivirals ( $n=125$, mean duration of antiviral treatment 60.1 months). ${ }^{66}$ At 5 years, the probability of HCC recurrence was significantly lower for the patients receiving antiviral treatment. Similarly, the probability of OS at 5 years was significantly higher in the combination group. Several studies and meta-analysis on the role of antiviral therapy following surgical resection have shown mixed results. ${ }^{67-70}$ There is a need for a well-designed prospective 
study to evaluate the benefit of antiviral therapy in patients undergoing ablation. ${ }^{71}$

In an RCT by Cui et al, 62 patients were randomized to receive RFA alone ( $n=32)$ or RFA+ cellular immunotherapy (CIT, $n=30$ ). The PFS was significantly higher in the combination group than the monotherapy group. ${ }^{72}$ No significant adverse effects were reported in patients receiving CIT. In another multicenter open-labeled RCT, 230 patients were randomized to two groups, one receiving definitive treatment (HR, ablation, or percutaneous ethanol injection) plus immunotherapy with cytokine-induced killer cells ( $n=115$ ) and other group not receiving immunotherapy. ${ }^{73}$ The median recurrence-free survival was significantly greater in the combination group (44 vs. 30 months). No serious adverse events were reported. In a double-blind, placebo-controlled trial, surgical resection $(n=900)$ or local ablation $(n=214)$ was followed by sorafenib $(n=556)$ or placebo $(n=558) .{ }^{74}$ There was no significant difference in the recurrence-free survival between the two groups.

In conclusion, the guidelines presented in two parts cover the most important areas related to ablation of HCC. These guidelines are expected to be useful for the practicing interventional radiologists in their day-to-day practice.

\section{Financial Disclosures}

None.

\section{Conflict of Interest}

None.

\section{References}

1 White DL, Thrift AP, Kanwal F, Davila J, El-Serag HB. Incidence of hepatocellular carcinoma in all 50 United States, from 2000 through 2012. Gastroenterology 2017;152(4):812-820.e5

2 Bruix J, Reig M, Sherman M. Evidence-based diagnosis, staging, and treatment of patients with hepatocellular carcinoma. Gastroenterology 2016;150(4):835-853

3 Heimbach JK, Kulik LM, Finn RS, et al. AASLD guidelines for the treatment of hepatocellular carcinoma. Hepatology 2018;67(1):358-380

4 Shiina S, Sato K, Tateishi R, et al. Percutaneous ablation for hepatocellular carcinoma: comparison of various ablation techniques and surgery. Can J Gastroenterol Hepatol 2018;2018:4756147

5 Atkins D, Best D, Briss PA, et al; GRADE Working Group. Grading quality of evidence and strength of recommendations. BMJ 2004;328(7454):1490

6 Kang TW, Lim HK, Lee MW, Kim YS, Choi D, Rhim H. Perivascular versus nonperivascular small HCC treated with percutaneous RF ablation: retrospective comparison of long-term therapeutic outcomes. Radiology 2014;270(3):888-899

7 de Baere T, Bessoud B, Dromain C, et al. Percutaneous radiofrequency ablation of hepatic tumors during temporary venous occlusion. AJR Am J Roentgenol 2002;178(1):53-59

8 de Baere T, Deschamps F, Briggs P, et al. Hepatic malignancies: percutaneous radiofrequency ablation during percutaneous portal or hepatic vein occlusion. Radiology 2008;248(3):1056-1066

9 Yamasaki T, Kurokawa F, Shirahashi H, Kusano N, Hironaka K, Okita K. Percutaneous radiofrequency ablation therapy for patients with hepatocellular carcinoma during occlusion of hepatic blood flow. Comparison with standard percutaneous radiofrequency ablation therapy. Cancer 2002;95(11):2353-2360

10 Miyamoto N, Tsuji K, Sakurai Y, et al. Percutaneous radiofrequency ablation for unresectable large hepatic tumours during hepatic blood flow occlusion in four patients. Clin Radiol 2004;59(9):812-818

11 Dodd GD III, Dodd NA, Lanctot AC, Glueck DA. Effect of variation of portal venous blood flow on radiofrequency and microwave ablations in a blood-perfused bovine liver model. Radiology 2013;267(1):129-136

12 Wright AS, Sampson LA, Warner TF. Mahvi DM, Lee FT Jr. Radiofrequency versus microwave ablation in a hepatic porcine model. Radiology 2005;236(1):132-139

13 Dou JP, Yu J, Yang XH, et al. Outcomes of microwave ablation for hepatocellular carcinoma adjacent to large vessels: a propensity score analysis. Oncotarget 2017;8(17):28758-28768

14 Loriaud A, Denys A, Seror O, et al. Hepatocellular carcinoma abutting large vessels: comparison of four percutaneous ablation systems. Int J Hyperthermia 2018;34(8):1171-1178

15 van Tilborg AA, Scheffer HJ, de Jong MC, et al. MWA versus RFA for perivascular and peribiliary CRLM: a retrospective patientand lesion-based analysis of two historical cohorts. Cardiovasc Intervent Radiol 2016;39(10):1438-1446

16 Sutter O, Calvo J, N'Kontchou G, et al. Safety and efficacy of irreversible electroporation for the treatment of hepatocellular carcinoma not amenable to thermal ablation techniques: a retrospective single-center case series. Radiology 2017;284(3):877-886

17 Kalra N, Gupta P, Gorsi U, et al. Irreversible electroporation for unresectable hepatocellular carcinoma: initial experience. Cardiovasc Intervent Radiol 2019;42(4):584-590

18 Bhutiani N, Philips P, Scoggins CR, McMasters KM, Potts MH, Martin RCG. Evaluation of tolerability and efficacy of irreversible electroporation (IRE) in treatment of ChildPugh B (7/8) hepatocellular carcinoma (HCC) HPB (Oxford) 2016;18(7):593-599

19 Cheng RG, Bhattacharya R, Yeh MM, Padia SA. Irreversible electroporation can effectively ablate hepatocellular carcinoma to complete pathologic necrosis. J Vasc Interv Radiol 2015;26(8):1184-1188

20 Mafeld S, Wong JJ, Kibriya N, et al. Percutaneous irreversible electroporation (IRE) of hepatic malignancy: a bi-institutional analysis of safety and outcomes. Cardiovasc Intervent Radiol 2019;42(4):577-583

21 Huang YZ, Zhou SC, Zhou H, Tong M. Radiofrequency ablation versus cryosurgery ablation for hepatocellular carcinoma: a meta-analysis. Hepatogastroenterology 2013;60(125):1131-1135

22 Wang C, Wang H, Yang W, et al. Multicenter randomized controlled trial of percutaneous cryoablation versus radiofrequency ablation in hepatocellular carcinoma. Hepatology 2015;61(5):1579-1590

23 Kim R, Kang TW, Cha DI, et al. Percutaneous cryoablation for perivascular hepatocellular carcinoma: therapeutic efficacy and vascular complications. Eur Radiol 2019;29(2): 654-662

24 Cha SY, Kang TW, Min JH, et al. RF ablation versus cryoablation for small perivascular hepatocellular carcinoma: propensity score analyses of mid-term outcomes. Cardiovasc Intervent Radiol 2020;43(3):434-444

25 Yoon JH, Lee EJ, Cha SS, et al. Comparison of gadoxetic acid-enhanced MR imaging versus four-phase multi-detector row computed tomography in assessing tumor regression after radiofrequency ablation in subjects with hepatocellular carcinomas. J Vasc Interv Radiol 2010;21(3):348-356 
26 Lekht I, Gulati M, Nayyar M, et al. Role of contrast-enhanced ultrasound (CEUS) in evaluation of thermal ablation zone. Abdom Radiol (NY) 2016;41(8):1511-1521

27 Du J, Li HL, Zhai B, Chang S, Li FH. Radiofrequency ablation for hepatocellular carcinoma: utility of conventional ultrasound and contrast-enhanced ultrasound in guiding and assessing early therapeutic response and short-term follow-up results. Ultrasound Med Biol 2015;41(9):2400-2411

$28 \mathrm{Xu}$ EJ, Lv SM, Li K, et al. Immediate evaluation and guidance of liver cancer thermal ablation by three-dimensional ultrasound/contrast-enhanced ultrasound fusion imaging. Int J Hyperthermia 2018;34(6):870-876

29 Minami Y, Minami T, Hagiwara S, et al. Ultrasound-ultrasound image overlay fusion improves real-time control of radiofrequency ablation margin in the treatment of hepatocellular carcinoma. Eur Radiol 2018;28(5):1986-1993

30 Rajesh S, Mukund A, Arora A, Jain D, Sarin SK. Contrastenhanced US-guided radiofrequency ablation of hepatocellular carcinoma. J Vasc Interv Radiol 2013;24(8):1235-1240

31 Rhim H, Dodd GD III. Radiofrequency thermal ablation of liver tumors. J Clin Ultrasound 1999;27(5):221-229

32 Nguyen Q Justaniah A, Sarwar A, Ahmed M. Does immediate peri-hepatic hematoma or contrast extravasation after hepatic tumor ablation require angiography? J Vasc Interv Radiol 2016;27:S125

33 Gao QZ, Wang ZW, Pan J, Shi HF, Zhang XB, Jin ZY. [The occurrence and clinical significance of contrast agent spillover on immediate enhanced CT reexamination after radiofrequency ablation of liver cancer]. Zhonghua Gan Zang Bing Za Zhi 2018;26(7):503-507

34 Livraghi T, Solbiati L, Meloni MF, Gazelle GS, Halpern EF, Goldberg SN. Treatment of focal liver tumors with percutaneous radio-frequency ablation: complications encountered in a multicenter study. Radiology 2003;226(2):441-451

35 Chuang $\mathrm{CH}$, Chen CY, Tsai HM. Hepatic infarction and hepatic artery pseudoaneurysm with peritoneal bleeding after radiofrequency ablation for hepatoma. Clin Gastroenterol Hepatol 2005;3(11):A23

36 Datta RV. Intrahepatic pseudoaneurysm after radiofrequency ablation of liver lesion. Int Surg 2008;93(6):381-384

37 Curley SA, Marra P, Beaty K, et al. Early and late complications after radiofrequency ablation of malignant liver tumors in 608 patients. Ann Surg 2004;239(4):450-458

38 Akahane M, Koga $\mathrm{H}$, Kato N, et al. Complications of percutaneous radiofrequency ablation for hepato-cellular carcinoma: imaging spectrum and management. Radiographics 2005;25(Suppl 1) :S57-S68

39 Vogel A, Cervantes A, Chau I, et al. Hepatocellular carcinoma: ESMO Clinical Practice Guidelines for diagnosis, treatment and follow-up. Ann Oncol 2018;29(Suppl 4) :iv238-iv255

40 Dromain C, de Baere T, Elias D, et al. Hepatic tumors treated with percutaneous radio-frequency ablation: CT and MR imaging follow-up. Radiology 2002;223(1):255-262

41 Lim HK, Choi D, Lee WJ, et al. Hepatocellular carcinoma treated with percutaneous radio-frequency ablation: evaluation with follow-up multiphase helical CT. Radiology 2001;221(2):447-454

42 Liu W, Zheng Y, Zou R, et al. Impact of follow-up interval on patients with hepatocellular carcinoma after curative ablation. BMC Cancer 2018;18(1):1186

43 Boas FE, Do B, Louie JD, et al. Optimal imaging surveillance schedules after liver-directed therapy for hepatocellular carcinoma. J Vasc Interv Radiol 2015;26(1):69-73

44 Mikami S, Tateishi R, Akahane M, et al. Computed tomography follow-up for the detection of hepatocellular carcinoma recurrence after initial radiofrequency ablation: a single-center experience. J Vasc Interv Radiol 2012;23(10):1269-1275

45 Granata V, Petrillo M, Fusco R, et al. Surveillance of HCC patients after liver RFA: role of MRI with hepatospecific contrast versus three-phase CT scan-experience of high volume oncologic institute. Gastroenterol Res Pract 2013;2013:469097

46 Sainani NI, Gervais DA, Mueller PR, Arellano RS. Imaging after percutaneous radiofrequency ablation of hepatic tumors: Part 2, Abnormal findings. AJR Am J Roentgenol 2013;200(1):194-204

47 Gupta P, Kalra N, Gulati A, et al. Response assessment following image-guided therapy of hepatocellular carcinoma. J Clin Interv Radiol 2020;4(2):88-97

48 Mohamed RE, Amin MA, Omar HM. Apparent diffusion coefficient and dynamic contrast-enhanced MRI as reliable biomarkers for evaluating response to locoregional therapy in hepatocellular carcinoma patients. Egypt J Radiol Nucl Med. 2018;49:914-927

49 Mahmoud BEMH, Elkholy SF, Nabeel MM, et al. Role of MRI in the assessment of treatment response after radiofrequency and microwave ablation therapy for hepatocellular carcinoma. Egypt J Radiol Nucl Med 2016;47:377-385

50 Anderson GS, Brinkmann F, Soulen MC, Alavi A, Zhuang H. FDG positron emission tomography in the surveillance of hepatic tumors treated with radiofrequency ablation. Clin Nucl Med 2003;28(3):192-197

51 Chaudhry M, McGinty KA, Mervak B, et al. The LI-RADS version 2018 MRI treatment response algorithm: evaluation of ablated hepatocellular carcinoma. Radiology 2020;294(2):320-326

52 Seo N, Kim MS, Park MS, et al. Evaluation of treatment response in hepatocellular carcinoma in the explanted liver with liver imaging reporting and data system version 2017. Eur Radiol 2020;30(1):261-271

53 Liao WJ, Shi M, Chen JZ, Li AM. Local recurrence of hepatocellular carcinoma after radiofrequency ablation. World J Gastroenterol 2010;16(40):5135-5138

54 Chan AC, Chan SC, Chok KS, et al. Treatment strategy for recurrent hepatocellular carcinoma: salvage transplantation, repeated resection, or radiofrequency ablation? Liver Transpl 2013;19(4):411-419

55 Kalra N, Gupta P, Chawla Y, Khandelwal N. Locoregional treatment for hepatocellular carcinoma: the best is yet to come. World J Radiol 2015;7(10):306-318

$56 \mathrm{Ni} \mathrm{JY}$, Liu SS, Xu LF, Sun HL, Chen YT. Meta-analysis of radiofrequency ablation in combination with transarterial chemoembolization for hepatocellular carcinoma. World J Gastroenterol 2013;19(24):3872-3882

57 Peng ZW, Zhang YJ, Chen MS, et al. Radiofrequency ablation with or without transcatheter arterial chemoembolization in the treatment of hepatocellular carcinoma: a prospective randomized trial. J Clin Oncol 2013;31(4):426-432

58 Abdelaziz AO, Abdelmaksoud AH, Nabeel MM, et al. Transarterial chemoembolization combined with either radiofrequency or microwave ablation in management of hepatocellular carcinoma. Asian Pac J Cancer Prev 2017;18(1):189-194

59 Song MJ, Bae SH, Lee JS, et al. Combination transarterial chemoembolization and radiofrequency ablation therapy for early hepatocellular carcinoma. Korean J Intern Med (Korean Assoc Intern Med) 2016;31(2):242-252

60 Chen QF, Jia ZY, Yang ZQ, Fan WL, Shi HB. Transarterial chemoembolization monotherapy versus combined transarterial chemoembolization-microwave ablation therapy for hepatocellular carcinoma tumors $\leq 5 \mathrm{~cm}$ : a propensity analysis at a single center. Cardiovasc Intervent Radiol 2017;40(11):1748-1755

61 Kamal A, Barakat E, ElMoez A, Mawad M, El-Fouly N, Shaker M. Combined radiofrequency and chemoembolization vs. chemoembolization in management of hepatocellular carcinoma. Hepatoma Res 2015;1:19-23

62 Xu RC, Liu HC, Li JL, et al. Long-term outcome of transcatheter arterial chemoembolization after radiofrequency ablation as 
a combined therapy for Chinese patients with hepatocellular carcinoma. Curr Med Res Opin 2015;31(8):1553-1560

63 Morimoto M, Numata K, Kondou M, Nozaki A, Morita S, Tanaka K. Midterm outcomes in patients with intermediate-sized hepatocellular carcinoma: a randomized controlled trial for determining the efficacy of radiofrequency ablation combined with transcatheter arterial chemoembolization. Cancer 2010;116(23):5452-5460

64 Dong W, Zhang T, Wang ZG, Liu H. Clinical outcome of small hepatocellular carcinoma after different treatments: a metaanalysis. World J Gastroenterol 2014;20(29):10174-10182

65 Jinhua H. RCT of TAE with simultaneously combined thermal ablation for large hepatocellular carcinoma (NCT02964260)

66 Sohn W, Kang TW, Choi S-K, et al. Effect of oral antiviral treatment on long-term outcomes of radiofrequency ablation therapy for hepatitis B virus-related hepatocellular carcinoma. Oncotarget 2016;7(30):47794-47807

67 ANRS collaborative study group on hepatocellular carcinoma (ANRS CO22 HEPATHER CC and CC cohorts). Lack of evidence of an effect of direct-acting antivirals on the recurrence of hepatocellular carcinoma: Data from three ANRS cohorts. J Hepatol 2016;65:734-740

68 Kobayashi M, Suzuki F, Fujiyama S, et al. Sustained virologic response by direct antiviral agents reduces the incidence of hepatocellular carcinoma in patients with HCV infection. J Med Virol 2017;89(3):476-483
69 Petta S, Cabibbo G, Barbara M, et al; Italian Liver Cancer (ITA. LI.CA) Group. Hepatocellular carcinoma recurrence in patients with curative resection or ablation: impact of HCV eradication does not depend on the use of interferon. Aliment Pharmacol Ther 2017;45(1):160-168

70 Cabibbo G, Petta S, Calvaruso V, et al; Rete Sicilia Selezione Terapia - HCV (RESIST-HCV). Is early recurrence of hepatocellular carcinoma in HCV cirrhotic patients affected by treatment with direct-acting antivirals? A prospective multicentre study. Aliment Pharmacol Ther 2017;46(7):688-695

71 European Association for the Study of the Liver. EASL clinical practice guidelines: management of hepatocellular carcinoma. J Hepatol 2018;69(1):182-236

72 Cui J, Wang N, Zhao H, et al. Combination of radiofrequency ablation and sequential cellular immunotherapy improves progression-free survival for patients with hepatocellular carcinoma. Int J Cancer 2014;134(2):342-351

73 Lee JH, Lee JH, Lim YS, et al. Adjuvant immunotherapy with autologous cytokine-induced killer cells for hepatocellular carcinoma. Gastroenterology 2015;148(7):1383-91.e6

74 Bruix J, Takayama T, Mazzaferro V, et al; STORM investigators. Adjuvant sorafenib for hepatocellular carcinoma after resection or ablation (STORM): a phase 3, randomised, double-blind, placebo-controlled trial. Lancet Oncol 2015;16(13):1344-1354 